DE

M E D I C I N A

T R O P I C A L

$\mathrm{DE}$

S ÃO PAULO

JOURNAL OF THE SÃO PAULO INSTITUTE OF TROPICAL MEDICINE

\section{Students' HPV vaccination rates are associated with demographics, sexuality, and source of advice but not level of study in medical school}

\author{
Miriam da Silva Wanderley ${ }^{\oplus 1}$, Dejano Tavares Sobral ${ }^{\circledR 2}$, Lívia de Azevedo \\ Levino $^{\left({ }^{\circ} 3\right.}$, Luísa de Assis Marques ${ }^{(1)}{ }^{3}$, Mateus Silva Feijó ${ }^{\left({ }^{\circledR} 3\right.}$, Nathália Regina \\ Cardoso Aragão 3
}

\section{ABSTRACT}

This study aimed to explore how medical students differ regarding the HPV vaccination status according to their demographics, sexuality, medical school year and sources of information regarding the vaccine. The cross-sectional survey included 379 participants from medical school year 1 to 6 , in a medical school in Brasilia. Statistical analyses of the data obtained from a questionnaire analyzed contingency tables and highlighted odds ratios effect sizes. The results showed that among all the participants, $80(21.1 \%)$ were vaccinated against HPV, 215 (58.7\%) were not vaccinated but wanted to be and $84(22.2 \%)$ were neither vaccinated nor wanted to be vaccinated. Female gender $(\mathrm{OR}=5.88,95 \%$ CI 3.36-10.30), parental advice $(\mathrm{OR}=6.95,95 \% \mathrm{CI}=3.97-12.16)$, and absence of sexual initiation before 16 years of age $(\mathrm{OR}=3.04,95 \% \mathrm{CI}=1.05-8.77)$ were positively associated with HPV-vaccinated students. In parallel, female gender $(\mathrm{OR}=4.74,95 \% \mathrm{CI}=2.38-9.44)$, parental advice $(\mathrm{OR}=3.50,95 \% \mathrm{CI}=1.20-10.22)$, and reporting two or more recent sexual partners $(\mathrm{OR}=2.03,95 \% \mathrm{CI}=1.06-3.88)$ were positively associated with the intention to be vaccinated among unvaccinated students. The high cost of the vaccine was perceived as a barrier among those respondents who wished to be vaccinated. Additionally, among the $84(81.3 \%$ male) students who admitted unwillingness to be vaccinated, approximately two-thirds cited the feeling to be safe, lack of counseling, or low efficacy of the vaccine as the reasons for their reluctance. In conclusion, vaccination coverage was low among these medical students. Nevertheless, female gender, personal advice, and safe sex were the main factors associated with higher levels of vaccination and vaccine acceptance.

KEYWORDS: Medical students. Papillomavirus vaccination. Sexual behavior. Surveys and questionnaires. Cross-sectional study.

\section{INTRODUCTION}

Human papillomavirus (HPV) is the most prevalent viral infection of the reproductive tract. HPV is the causal agent of a variety of conditions in both men and women, some of which may progress to cancer. Persistent HPV infection may result in disease, although acute infections may resolve spontaneously without symptoms or treatment ${ }^{1}$. In women, persistent infection with HPV-16 and HPV-18 genotypes (among others) can lead to premalignant lesions that may progress to cervical cancer if left untreated ${ }^{2}$. Moreover, HPV infection is also a causal agent of the majority of oropharyngeal and anogenital cancers and other diseases in both genders ${ }^{3}$. 
The United Kingdom introduced a nationwide HPV immunization program in $2008^{4}$. In Brazil, the use of the quadrivalent vaccine in the national vaccination program started in 2014 and initially targeted girls aged 9-13 years old with a three-dose schedule ${ }^{5}$. Since 2017, the HPV vaccine became available in the public health system for females aged 9-14 years old and males aged 11-14 years old in a two-dose schedule ${ }^{5}$. The efficacy and safety of the quadrivalent vaccine has been reaffirmed by the World Health Organization experts ${ }^{6}$.

Evaluating the vaccination status and perceptions of medical students is crucial as their attitudes as future health providers could influence their patients' adherence to vaccination programs against HPV. Most relevant studies have focused on the knowledge and beliefs of the participants regarding the vaccine and its use, with no information on vaccination rates ${ }^{7}$. Nevertheless, a study in Scotland revealed a sharp increase in the vaccination rates of female medical students within a year after the beginning of the national immunization program ${ }^{4}$. Moreover, a survey from the United States found a $44 \%$ vaccination rate among medical school students, and the authors asserted the positive role of provider's recommendations ${ }^{8}$. Additionally, a Brazilian study evaluated the level of knowledge and use of the vaccine among medical (and literature) students. The authors highlighted the low vaccination coverage among the students and sex differences in the vaccination rate, familiarity with, and interest in being vaccinated ${ }^{9}$.

As a further contribution to the topic, the current study aimed to explore how medical students differ regarding HPV vaccination status according to their demographics, sexuality, medical school year, and sources of information regarding the vaccine. We used a survey questionnaire to pursue the following research questions:

a) does the students' vaccination status relate to their demographics (age, sex, and family income) and level of medical studies?

b) are the students' responses about personal or media sources of information regarding the HPV vaccine related to their vaccination status?

c) do students who report early sexual intercourse or multiple sexual partners have a lower rate of HPV vaccination?

\section{METHODS}

This study was a cross-sectional survey on a population of undergraduate students from the first to the sixth year of the Faculty of Medicine, University of Brasilia, a federal public university. We based the sample size calculation on the total of 521 students who were enrolled in for courses and activities in 2017. The sample size needed for a satisfactory response rate was 350 students (95\% confidence level, $3 \%$ confidence interval).

The Ethics Committee on Research in Human Beings of the Faculty of Medicine (1.989.835) approved the study.

In the second semester of 2017, during classes, the survey questionnaires that were created based on a literature review ${ }^{7,10-12}$ were applied by four authors of the study, and 392 students returned the questionnaires. Thirteen cases were excluded from the study (six because the respondents omitted information about HPV vaccination and seven because they were younger than 18 years old). Thus, the analyses included 379 questionnaires.

Categorical data were reported as counts and frequencies. These data were checked using contingency analyses, which applied the qui-square test that highlighted the magnitude of odds ratios (ORs), 95\% confidence intervals (CIs), or and the Fisher's exact tests. The analyses were carried out with the SPSS software, version 17 (IBM, New York, USA). The respondents were grouped for statistical purposes, as shown in Table 1.

Table 1 - Grouping of respondents for statistical purposes.

\begin{tabular}{ll}
\hline Attribute & \multicolumn{1}{c}{ Groups } \\
\hline Age range & $<24$ years; 24 years or older. \\
\hline Family income & $\begin{array}{l}\text { < Five times the minimum wage; five times } \\
\text { the minimum wage or more. }\end{array}$ \\
\hline Sexual initiation & Before 16 years of age; later or none. \\
\hline Sexual partners & None; one; two or more (per year). \\
\hline $\begin{array}{l}\text { Vaccination } \\
\text { status }\end{array}$ & $\begin{array}{l}\text { Vaccinated; not vaccinated but willing to be } \\
\text { vaccinated; not vaccinated and no desire to } \\
\text { be vaccinated. }\end{array}$ \\
\hline $\begin{array}{l}\text { Sources of } \\
\text { advice about } \\
\text { the vaccine }\end{array}$ & $\begin{array}{l}\text { None; personal (parent, friend, doctor, } \\
\text { or health professional); media (internet, } \\
\text { printed material, television or government } \\
\text { campaigns). }\end{array}$ \\
\hline
\end{tabular}

\section{RESULTS}

\section{Students' profiles}

The mean age of the 379 participants was $21.8 \pm 3.1$ years (SD), and $81(21.6 \%)$ students were older than 23 years. Only 161 participants $(42.5 \%)$ were female. Regarding the level of medical studies, 134 (35.4\%) were in their $1^{\text {st }}$ or $2^{\text {nd }}$ year, $137(36.1 \%)$ were in their $3^{\text {rd }}$ or $4^{\text {th }}$ year, and $108(28.5 \%)$ were in their $5^{\text {th }}$ or the $6^{\text {th }}$ year of the medical school. Concerning the family income, 279 (75.8\%) reported earnings of five or more Brazilian minimum wages. Among the 372 respondents, 97 (26.1\%) were celibate, 93 
$(25 \%)$ had an average of two or more sexual partners per year, and $44(11.7 \%)$ reported the first sexual intercourse under the age of 16 . Additionally, $76 \%$ of the sexually active students reported the use of barrier contraceptive methods. Furthermore, the vast majority $(93.7 \%)$ of the participants were aware of the public availability of the HPV vaccine, but less than half $(48.9 \%)$ knew that it was available to both genders.

\section{HPV vaccination contingencies}

Among all the participants, 80 (21.1\%) were vaccinated against HPV, 215 (58.7\%) were not vaccinated but desired to be and $84(22.2 \%)$ were neither vaccinated nor wanted to be vaccinated. The students' distribution among these three vaccination categories was significantly associated with sex (Cramer's V $=.412, \mathrm{p}<.001$ ), reported source of information (media, personal, or a mix) about the vaccine (Cramer's $\mathrm{V}=.276, \mathrm{p}<.001$ ), and age bracket (Cramer's $\mathrm{V}=.139$, $\mathrm{p}=.026$ ) but not with the level of medical studies (Cramer's $\mathrm{V}=.100, \mathrm{p}=.149)$. Notably, older students $(\geq 24$ years of age), in comparison with younger participants, had a lower percentage of vaccination (13.4 vs. $23.2 \%$ ) and a higher percentage of individuals who avoided vaccination (31.7 vs. $19.5 \%$ ). Table 2 shows that the majority of vaccinated students reported having a personal source of information only.

Comparing the rates of vaccination among the participants, the vaccine acceptance was positively and significantly associated with parental advice ( 52.0 vs. $13.5 \%$; phi $=.376$, $\mathrm{p}<.001$ ), female sex (37.3 vs. 9.2\%; phi $=.340, \mathrm{p}<.001)$, and delayed or no sexual initiation (23.3 vs. $9.1 \%$; $\mathrm{phi}=.112$, p= .031). In contrast, vaccination was not significantly associated with younger age ( $\mathrm{phi}=.099, \mathrm{p}=.054)$, higher level of medical studies ( $\mathrm{phi}=-.040, \mathrm{p}=.435$ ), single partner, celibate status (phi $=-.030, \mathrm{p}=.560)$, or higher family income $(\mathrm{phi}=.013$, $\mathrm{p}=.790$ ). Notably, except for parental advice, no other source of information (personal or media) showed a significant positive association with vaccination. Table 3 highlights the differential ORs of the associations (regarding vaccination) with parental advice, female sex, early sexual initiation and younger age.

Comparing proportions of students willing or not to be vaccinated, significant positive associations were found for female sex (89.1 vs. $63.1 \%$; phi $=.273, \mathrm{p}<.0001)$ and parental advice (88.9 vs. $69.6 \%$; phi $=.140, \mathrm{p}=.0167$ ),

Table 2 - Medical students' vaccine status and sources of information about the HPV vaccine.

\begin{tabular}{|c|c|c|c|c|}
\hline \multirow[b]{2}{*}{ Information sources } & \multicolumn{4}{|c|}{ Students' vaccine status } \\
\hline & $\begin{array}{c}\text { Not vaccinated } \\
\text { not willing to }(n, \%)\end{array}$ & $\begin{array}{c}\text { Not vaccinated } \\
\text { but willing to }(n, \%)\end{array}$ & $\begin{array}{l}\text { Vaccinated } \\
(\mathrm{n}, \%)\end{array}$ & $\begin{array}{l}\text { Total } \\
\mathrm{n}(\%)\end{array}$ \\
\hline None & $6(46.2)$ & $6(46.2)$ & $6(7.7)$ & $13(3.4)$ \\
\hline Media only (A) & $51(30.2)$ & $102(60.4)$ & $16(9.5)$ & $169(44.6)$ \\
\hline $\operatorname{Mix}(A \& B)$ & $10(13.0)$ & $54(70.1)$ & $13(16.9)$ & 77 (20.3) \\
\hline Personal only (B) & $17(14.2)$ & $53(44.2)$ & $50(41.7)$ & $120(31.7)$ \\
\hline Total & $84(22.2)$ & $215(56.7)$ & $80(21.1)$ & $379(100)$ \\
\hline
\end{tabular}

A) printed material, Internet, TV or government campaign; B) parent, friend, doctor or health professional. Measure of association: Cramer's V; value: $0.276, p<.001$

Table 3 - HPV vaccination status among medical students grouped according to four categories of retrospective influence on vaccine use $(\mathrm{N}=379)$.

\begin{tabular}{|c|c|c|c|c|c|c|}
\hline \multirow{2}{*}{ Categories } & \multirow{2}{*}{ Groups } & \multicolumn{2}{|c|}{ Vaccination } & \multicolumn{2}{|c|}{ Odds ratio } & \multirow{2}{*}{$\begin{array}{l}\text { Fisher's } \\
\text { exact test }\end{array}$} \\
\hline & & No & Yes & Value & $95 \% \mathrm{Cl}$ & \\
\hline \multirow{2}{*}{ Parental advice } & Yes & 36 & 39 & \multirow{2}{*}{6.95} & \multirow{2}{*}{$3.97-12.16$} & \multirow{2}{*}{$<.0001$} \\
\hline & No & 263 & 41 & & & \\
\hline \multirow{2}{*}{ Sex } & Female & 101 & 60 & \multirow[t]{2}{*}{5.88} & \multirow[t]{2}{*}{$3.36-10.30$} & \multirow{2}{*}{$<.0001$} \\
\hline & Male & 198 & 20 & & & \\
\hline \multirow{2}{*}{ Sexual initiation } & $<16$ years & 40 & 4 & \multirow{2}{*}{.33} & \multirow{2}{*}{$.11-.95$} & \multirow{2}{*}{.0317} \\
\hline & Later or none & 250 & 76 & & & \\
\hline \multirow{2}{*}{ Age range } & $<24$ years old & 228 & 69 & \multirow{2}{*}{1.95} & \multirow{2}{*}{$.98-3.89$} & \multirow{2}{*}{.0659} \\
\hline & $\geq 24$ years old & 71 & 11 & & & \\
\hline
\end{tabular}


Table 4 - Desire of HPV vaccination status among medical students grouped according to four categories ordered by decreasing odds of a relationship ( $\mathrm{N}=299)$.

\begin{tabular}{|c|c|c|c|c|c|c|}
\hline \multirow{2}{*}{ Categories } & \multirow{2}{*}{ Groups } & \multicolumn{2}{|c|}{ Wants vaccine } & \multicolumn{2}{|c|}{ Odds ratio } & \multirow{2}{*}{$\begin{array}{c}\text { Fisher's } \\
\text { exact test }\end{array}$} \\
\hline & & No & Yes & Value & $95 \% \mathrm{Cl}$ & \\
\hline \multirow{2}{*}{ Sex } & Female & 11 & 90 & \multirow{2}{*}{4.74} & \multirow{2}{*}{$2.38-9.44$} & \multirow{2}{*}{$<.0001$} \\
\hline & Male & 73 & 126 & & & \\
\hline \multirow{2}{*}{ Parental advice } & Yes & 4 & 32 & \multirow{2}{*}{3.50} & \multirow{2}{*}{$1.20-10.22$} & \multirow{2}{*}{.0167} \\
\hline & No & 80 & 183 & & & \\
\hline \multirow{2}{*}{ Sexual partners } & Two or more & 14 & 61 & \multirow{2}{*}{2.03} & \multirow{2}{*}{$1.06-3.88$} & \multirow{2}{*}{.0371} \\
\hline & One or none & 69 & 148 & & & \\
\hline \multirow{2}{*}{ Age range } & $<24$ years old & 58 & 170 & \multirow{2}{*}{1.69} & \multirow{2}{*}{$.96-2.99$} & \multirow{2}{*}{.0715} \\
\hline & $\geq 24$ years old & 26 & 45 & & & \\
\hline
\end{tabular}

while a negative association was found for single partner/ celibate status (68.2 vs. $81.3 \%$; phi $=-.127, \mathrm{p}=.0371)$. In contrast, no significant associations were found between willing to be vaccinated and younger age (74.6 vs. $63.4 \%$; phi $=.106, \mathrm{p}=.071)$, higher level of medical studies $(64.8$ vs. $74.9 \%$; phi $=.102, \mathrm{p}=.090)$, sexual initiation before 16 years old (70.0 vs. $71.8 \%$; phi $=-.0102, \mathrm{p}=.851)$, or higher family income (73.1 vs. $71.8 \%$; phi= $.012, \mathrm{p}=.878)$. Table 4 highlights the decreasing odds ratios (posture regarding vaccination) for female sex, parental advice, multiple partners and younger age.

Among the 299 unvaccinated students, those willing to be vaccinated (41.9\% females) also differed from those who did not want to be vaccinated ( $86.9 \%$ males), both in the relative frequency and the willingness to report the reasons for their reluctance. Only $58.6 \%$ of the students gave a reason in the first group (those who wanted to be vaccinated), in comparison with $89.3 \%$ who gave a reason in the second group. Out of ten listed reasons, the following four were selected by at least $10 \%$ of respondents from one of the groups: excessive cost of the vaccine, not being advised about vaccination, feeling safe from the infection, and the low efficacy of the vaccine. Table 5 highlights the differences in the frequencies between the two groups for the seven most cited reasons not to be vaccinated against HPV.

\section{DISCUSSION}

This study carried out with undergraduate medical students shows significant differences in the HPV vaccination status according to sex, sexual behavior and source of information about the vaccine. The vaccination rates among female medical students in Brasilia and Rio de Janeiro were comparable, but they were much lower than those found in Glasgow or Rochester ${ }^{4,8,9}$. One reason for the lower vaccination rate is the recent start $(2014)^{5}$ of the
Table 5 - Differences in reasons for avoiding HPV vaccination between students who want or not the vaccine $(\mathrm{N}=299)$.

\begin{tabular}{lcc}
\hline \multirow{2}{*}{ Reason cited for reluctance } & Want & Not want \\
\cline { 2 - 3 } & $\mathrm{n}(\%)$ & $\mathrm{n}(\%)$ \\
\hline The high cost of the vaccine & $55(25.6)$ & $9(10.7)$ \\
Not advised about vaccination & $25(11.6)$ & $19(22.5)$ \\
Doubt about vaccine effects & $18(8.4)$ & $3(3.6)$ \\
Feeling safe from infection & $14(6.5)$ & $20(23.8)$ \\
Low efficacy of vaccination & $10(4.6)$ & $13(15.5)$ \\
Other reasons & $4(1.9)$ & $11(13.1)$ \\
No reason cited & $89(41.4)$ & $9(10.7)$ \\
\hline
\end{tabular}

Measure of association: Cramer's V $=.487, p<.0001$.

national program of immunization against HPV in Brazil, in comparison with the initiation of the UK $(2008)^{4}$ or the US (2006) ${ }^{8}$ HPV vaccination. Less emphasis on women's reproductive health could be another reason.

The male vaccination rate was one-fourth of the female rate. In addition to the so-called vaccine feminization ${ }^{13}$, ascribed to the initial implementation strategy of the HPV vaccination, the male students may feel more protected from HPV infections, as suggested by one of the motives of unwillingness to be vaccinated and the prevalent use of sexual preservatives among the sexually active participants. Research carried out with university students in Turkey, Iran and India showed that $21.7 \%, 56 \%$ and $80 \%$ of students, respectively, shared the idea that condoms provide a total protection against $\mathrm{HPV}^{10,14,15}$ infections, inducing the belief that the use of sexual preservatives would eliminate the need for vaccination.

There was also no significant difference in the vaccination status among income groups, even though more than one-fourth of the unvaccinated students marked the high cost of the vaccine as a reason not to get vaccinated. 
The economic barrier is a reality in a country that provides the vaccine free of charge only for the primary school age group 5 . Most respondents were out of the target age group when the national immunization program started in 2014 and therefore would have to bear the cost of vaccination that is about one-third of the minimum wage for each dose. In addition to that barrier, other reasons (and underlying factors) may contribute not to get vaccinated, as suggested by the data shown in Table 5. It is noteworthy that one of these reasons was 'not being counseled about the vaccination', which was reported by one-fifth of the participants who did not want the vaccine.

An interesting finding was the dual role of the student's sexual behavior. Starting sexual intercourse before 16 years of age was negatively associated with vaccination. In contrast, among the unvaccinated respondents, the desire to be vaccinated was positively associated with two or more recent sexual partners. In either case, we suggest that a precautionary approach may support both associations. On the other hand, a study of American youth aged 15-24 years old showed that those who were sexually active had twice the intention of receiving the HPV vaccine when compared to the intentions of women who were not yet sexually active ${ }^{16}$. Additionally, a Spanish study showed that the prevalence of sexual risky behaviors was high in nonvaccinated university women and was primarily related to the non condom use. This finding contradicts the idea that vaccinated women could increase their sexual risks because of the protection ascribed to vaccination ${ }^{17}$.

Another interesting result was the strong relationship between either vaccination or the will to be vaccinated and parental advice about the vaccine. While knowledge acquisition was more common through the internet, the press, and government programs, vaccination advice was more effective when provided by parents. Although not surprising, this finding contrasts with the usual emphasis on the role of the health provider ${ }^{7}$. For example, a study reported that the vaccination rate is higher when the provider makes consistent recommendations and emphasizes cancer prevention ${ }^{18}$. However, a study in India showed that most doctors not only felt uncomfortable discussing the reproductive lives of girls with the parents of these adolescents but also believed that their patients would ignore a recommendation for vaccination ${ }^{19}$. We suggest that the planning of HPV vaccination campaigns place more importance on providing advice to the parents of boys and girls while reinforcing the role of well-prepared physicians and other health care providers.

As expected, older students ( $\geq 24$ years of age), in comparison with younger participants, had a lower percentage of vaccination and a higher percentage of vaccine avoidance. Older students may feel less conviction about the practicality of vaccination for themselves, perhaps due to a longer sexual life. Whatever the reasons, vaccination avoidance is detrimental because of the current evidence of the quadrivalent HPV vaccine efficacy and safety for both, young women ${ }^{20}$ and $m^{21}{ }^{21}$. One could consider the young adulthood as the final moment for the prevention of HPV-related-cancer.

Furthermore, among the participants in this study, the vaccination status was not significantly related to the level of medical training, which was similar to the findings of other authors $^{9,22}$ that a higher level of knowledge did not reflect in higher vaccination rates. On the other hand, Afonso et al. ${ }^{8}$ observed that students who received all doses of the vaccine had higher university grades than unvaccinated students.

Finally, the high likelihood of lifetime HPV makes vaccination of young adults, including college students, imperative $^{23}$. This issue points to the need for improved vaccine communication training for students in healthrelated professions, as discussed in the recent systematic literature review ${ }^{23}$. The multifaceted approach described by Schnaith et al. ${ }^{24}$ seems feasible and interesting. This approach includes a mix of information, demonstration, and role plays in students' curriculum to prepare them for communicating the HPV vaccine.

The study has some limitations. The cross-sectional design makes causal explanations difficult and a single medical school approach limits the generalization of results. Furthermore, the accuracy of self-reported data is uncertain. However, the satisfactory response rate supports the internal validity of the results, that are compatible with the current understanding of the problems.

In conclusion, this study confirms the low vaccination coverage among Brazilian medical students from a single federal university and affirms the male disparity in vaccine use. The findings emphasize the consistent association of female sex and parental advice with HPV vaccination. The results also indicate the role that sexual behavior factors play in vaccination status and suggest a preventive perspective as a significant predictor of vaccine use, even if it was observed in only a minority of the student body.

\section{REFERENCES}

1. Wong LP. Preventing cervical cancer through human papillomavirus vaccination: perspective from focus groups. J Low Genit Tract Dis. 2009;13:85-93.

2. de Sanjose S, Quint WG, Alemany L, Geraets DT, Klaustermeier JE, Lloveras B, et al. Human papillomavirus genotype attribution in invasive cervical cancer: a retrospective crosssectional worldwide study. Lancet Oncol. 2010;11:1048-56. 
3. World Health Organization. Human papillomavirus vaccines: WHO position paper, May 2017 - Recommendations. Vaccine. 2017;35:5753-5.

4. McCusker SM, Macqueen I, Lough G, Macdonald AI, Campbell

C, Graham SV. Gaps in detailed knowledge of human papillomavirus (HPV) and the HPV vaccine among medical students in Scotland. BMC Public Health. 2013;13:264.

5. Brasil. Ministério da Saúde. Secretaria de Vigilância em Saúde. Departamento de Vigilância das Doenças Transmissíveis. Coordenação-Geral do Programa Nacional de Imunizações. Informe técnico da ampliação da oferta das vacinas papilomavírus humano 6,11,16 e 18 (recombinante) - vacina HPV quadrivalente e meningocócica C (conjugada). Brasília: Ministério da Saúde; 2018. [cited 2019 Nov 21]. Available from: https://portalarquivos2.saude.gov.br/images/pdf/2018/ marco/14/Informe-T--cnico-HPV-MENINGITE.pdf

6. World Health Organization. Human papillomavirus vaccines: WHO position paper, May 2017. Wkly Epidemiol Rec. 2017:92:241-68.

7. Pan XF, Zhao ZM, Sun J, Chen F, Wen QL, Liu K, et al. Acceptability and correlates of primary and secondary prevention of cervical cancer among medical students in southwest China: implications for cancer education. PLoS One. 2014;9:e110353.

8. Afonso NM, Kavanagh MJ, Swanberg SM, Schulte JM, Wunderlich T, Lucia VC. Will they lead by example? Assessment of vaccination rates and attitudes to human papillomavirus in millennial medical students. BMC Public Health. 2017; 17:35.

9. Monteiro DL, Brollo LC, Souza TP, Santos JRP, Santos GR, Correa T, et al. Knowledge on the HPV vaccine among university students. Rev Inst Med Trop Sao Paulo. 2018;60:e46.

10. Ghojazadeh M, Azar ZF, Saleh P, Naghavi-Behzad M, Azar NG. Knowledge and attitude of Iranian university students toward human papilloma virus. Asian Pac J Cancer Prev. 2012;13:6115-9.

11. Deriemaeker H, Michielsen D, Reichman G, Devroey D, Cammu H. Knowledge about human papillomavirus and the human papillomavirus vaccine in Belgian students. Cent European J Urol. 2014;67:410-7.

12. Al-Shaikh GK, Almussaed EM, Fayed AA, Khan FH, Syed SB, Al-Tamimi TN, et al. Knowledge of Saudi female university students regarding cervical cancer and acceptance of the human papilloma virus vaccine. Saudi Med J. 2014;35:1223-30.

13. Daley EM, Vamos CA, Thompson EL, Zimet GD, Rosberger Z, Merrell L, et al. The feminization of HPV: how science, politics, economics and gender norms shaped U.S. HPV vaccine implementation. Papillomavirus Res. 2017;3:142-8.
14. Borlu A, Gunay O, Balci E, Sagiroglu M. Knowledge and attitudes of medical and non-medical Turkish university students about cervical cancer and HPV vaccination. Asian Pac J Cancer Prev. 2016;17:299-303.

15. Mehta S, Rajaram S, Goel G, Goel N. Awareness about human papillomavirus and its vaccine among medical students. Indian J Community Med. 2013;38:92-4.

16. Liddon NC, Hood JE, Leichliter JS. Intent to receive HPV vaccine and reasons for not vaccinating among unvaccinated adolescent and young women: findings from the 2006-2008 National Survey of Family Growth. Vaccine. 2012;30:2676-82.

17. Fernández-Feito A, Antón-Fernández R, Paz-Zulueta M. Conductas sexuales de riesgo y actividades preventivas frente al cáncer de cuello uterino en mujeres universitarias vacunadas frente al VPH. Aten Primaria. 2018;50:291-8.

18. Gilkey MB, Calo WA, Moss JL, Shah PD, Marciniak MW, Brewer NT. Provider communication and HPV vaccination: the impact of recommendation quality. Vaccine. 2016;34:1187-92.

19. Krupp K, Marlow LA, Kielmann K, Doddaiah N, Mysore $\mathrm{S}$, Reingold AL, et al. Factors associated with intentionto-recommend human papillomavirus vaccination among physicians Mysore, India, J Adolesc Health. 2010;46:379-84.

20. Wei L, Xie X, Liu J, Zhao Y, Chen W, Zhao D, et al. Efficacy of quadrivalent human papillomavirus vaccine against persistent infection and genital disease in Chinese women: a randomized, placebo-controlled trial with 78-month follow-up. Vaccine. 2019;37:3617-24.

21. Mikamo H, Yamagishi Y, Murata S, Yokohawa R, Han SR, Wakana A, et al. Efficacy, safety, and immunogenicity of a quadrivalent HPV vaccine in Japanese men: a randomized, Phase 3, placebocontrolled study. Vaccine. 2019;37:1651-8.

22. Yam PW, Lam PL, Chan TK, Chau KW, Hsu ML, Lim YM, et al. A cross-sectional study on knowledge, attitude and practice related to Human Papillomavirus vaccination for cervical cancer prevention between medical and non-medical students in Hong Kong. Asian Pac J Cancer Prev. 2017;18:1689-95.

23. Barnard M, Cole AC, Ward L, Gravlee E, Col ML, Compretta C. Interventions to increase uptake of the human papillomavirus vaccine in unvaccinated college students: a systematic literature review. Prev Med Rep. 2019;14:100884.

24. Schnaith AM, Evans EM, Vogt C, Tinsay AM, Schmidt TE, Tessier KM, et al. An innovative medical school curriculum to address human papillomavirus vaccine hesitancy. Vaccine. 2018;36:3830-5. 